Brit. J. industr. Med., 1955, 12, 126.

\title{
THE INFLUENCE OF INSPIRED AIR TEMPERATURE ON TOLERANCE TO WORK IN THE HEAT
}

\author{
BY \\ A. R. LIND \\ From the M.R.C. Climatic and Working Efficiency Unit, Department of Human Anatomy, Oxford
}

(RECEIVED FOR PUELICATION OCTOBER 23, 1954)

In mines rescue operations two main types of self-contained breathing apparatus are used by men working in irrespirable atmospheres. One of these types of apparatus uses compressed oxygen and the other liquid air as the source of oxygen supply for the wearer. Each type of apparatus has its own distinct advantages in use, and these advantages have long been recognized. The present investigation deals only with one aspect and this does not prejudice the merits of other aspects of the apparatus.

It is recognized that the temperature of the inspired air may well prove to be a limiting factor for working men. Haldane (1915) refers to the local respiratory effect of high wet-bulb temperatures. $\mathrm{He}$ found that when men were exposed to hot environments at a wet-bulb temperature of $45^{\circ} \mathrm{C}$. $\left(113^{\circ} \mathrm{F}\right.$.) they were able to breathe " pretty freely" even during hard work. Killick (1932) states that when subjects at rest in cool ambient conditions breathed hot, moist air they did not experience discomfort until the wet-bulb temperature of the inspired air reached 54.5 to $63^{\circ} \mathrm{C}$. (130 to $145^{\circ} \mathrm{F}$.), and found breathing tolerable until the wet-bulb temperature reached 59 to $65^{\circ} \mathrm{C}$. (138 to $150^{\circ} \mathrm{F}$.). When her subjects were working on an ergometer "at a rate equivalent to walking at 4 to $4 \frac{1}{2}$ m.p.h." these limits dropped to 51.5 to $54.5^{\circ} \mathrm{C}$. $\left(125\right.$ to $130^{\circ} \mathrm{F}$.) and 54.5 to $60^{\circ} \mathrm{C}$. $\left(130\right.$ to $140^{\circ} \mathrm{F}$.) wet-bulb temperatures, respectively.

Haldane also remarks that atmospheres which are very hot, but dry, can be breathed without great discomfort. This is confirmed by Killick, who found that, for subjects at rest, dry air of temperatures of up to $186^{\circ} \mathrm{C}$. $\left(367^{\circ} \mathrm{F}\right.$.) could be breathed in comfort, and the corresponding temperature for men working was $104 \cdot 5^{\circ} \mathrm{C}$. $\left(220^{\circ} \mathrm{F}\right.$.).

During a recent series of experiments, inspired air temperatures in the two types of breathing apparatus commonly worn in mines rescue work were recorded in hot environments under conditions simulating rescue operations, and their importance physiologically is emphasized in the results.

Description of the Circuits in Two Types of Apparatus

Apparatus 1.-This apparatus uses a cylinder of compressed oxygen as the source of supply of oxygen for the wearer. The oxygen is led from the cylinder to one compartment of a breathing bag. The gas then passes through a cooling device, and thence through a one-way valve to the mouthpiece. The exhaled gas passes through a non-return valve to the other compartment of the breathing bag. The two compartments are in communication at the bottom of the bag, in which is placed a charge of soda-lime. The gas must pass through the soda-lime, which removes the $\mathrm{CO}_{2}$, and the "regenerated "gas then mixes in the inhalation side of the breathing bag with the incoming oxygen from the cylinder. Soda-lime produces heat and moisture when it absorbs $\mathrm{CO}_{2}$, and the cooler is introduced to the circuit in an attempt to reduce the temperature of the absorbed air. The coolant used is sodium phosphate, which liquefies at about $35^{\circ} \mathrm{C}$. $\left(95^{\circ} \mathrm{F}\right.$.), so that in theory the temperature of the air in the circuit should not greatly exceed $35^{\circ} \mathrm{C}$. until all the coolant is liquefied.

Apparatus 2.-This apparatus uses liquid air as the source of supply of oxygen for the wearer. From the mouthpiece the exhaled gas is led through a non-return valve to a caustic-soda canister, where the $\mathrm{CO}_{2}$ is removed. The "regenerated" gas is then led to a breathing bag which consists of only one compartment, and acts solely as a reservoir. The gas is led from the breathing bag to the mouthpiece by way of a nonreturn valve. The liquid air evaporates in its container, and is introduced to the circuit at a point along the tube between the caustic-soda canister and the breathing bag. No cooler is incorporated, since the low temperature of evaporation of liquid air is sufficient to compensate for the heat evolved in the caustic-soda canister.

\section{Methods}

Thirty-six volunteer mine workers took part in the series of experiments. The men were divided into three 
teams of 12, each of which comprised six men wearing Apparatus 1 and six wearing Apparatus 2 ; each team was exposed three times to saturated still-air environments while performing a set task, and one team was exposed a fourth time, doing a different task. These tasks are described below. Six separate climates were investigated, involving 54 individual experiments on men wearing Apparatus 1 , and 54 individual experiments on men wearing Apparatus 2, where one task was performed. A further six individual experiments with each type of apparatus involved a different task.

The saturated temperatures in ${ }^{\circ} \mathrm{C}$. used were :-

\begin{tabular}{|c|c|c|c|}
\hline \multirow[t]{2}{*}{ Exposure } & \multicolumn{3}{|c|}{ Saturated Temperature $\mathrm{C}^{\circ *}$} \\
\hline & Team 1 & Team 2 & Team 3 \\
\hline $\begin{array}{l}1 \\
2 \\
3 \\
4\end{array}$ & $\begin{array}{l}29.4(85) \\
29.4(85) \\
32.2(90) \\
37.8(100) \dagger\end{array}$ & $\begin{array}{l}30 \cdot 8(87 \cdot 5) \\
30 \cdot 8(87 \cdot 5) \\
35 \quad(95)\end{array}$ & $\begin{array}{l}29.4(85) \\
33.6(92.5) \\
37.8(100)\end{array}$ \\
\hline
\end{tabular}

The air-speed in the room was less than $20 \mathrm{ft} . / \mathrm{min}$., although the effective air-speed was about $175 \mathrm{ft} . / \mathrm{min}$., due to the subject's movements. Room temperatures were thermostatically controlled in both dry- and wetbulb temperatures to $\pm 0 \cdot 5^{\circ} \mathrm{C}$.

Task A.- The task set in all but one exposure was of 65 minutes' duration, as follows :-

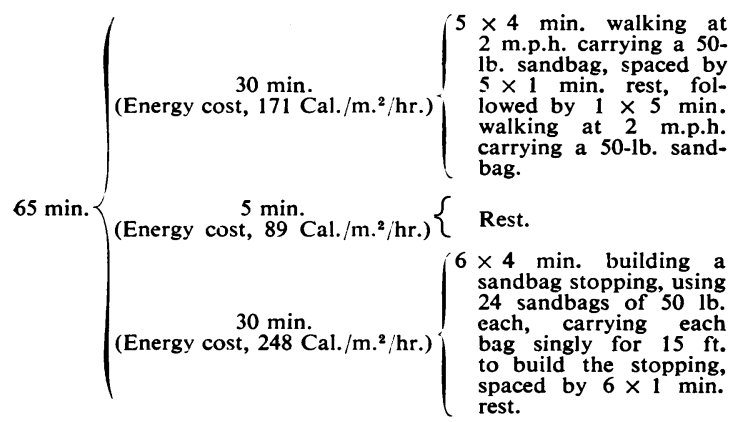

Task B.-This task was performed only once, in a highly saturated temperature, and was not expected to continue for 65 minutes. It comprised "sandbag stopping" cycles of five minutes each as shown in the second half of Task $A$ and was continued until the men were approaching their limit of tolerance.

Inspired air temperatures were taken once during each one-minute rest, and twice during the five-minute rest, until the end of the 65 minutes or until the men were considered unable to continue, or until they stopped voluntarily. The inspired air temperature was taken by a 30 s.w.g. copper-constantan thermocouple situated in the flexible tubing leading to the mouthpiece. The site for the thermocouple was chosen about 9 in. from the mouthpiece because the valve is not in the mouthpiece, and some temperature fluctuation occurs near the mouthpiece itself on the inspiration side due to pressure and convection currents on expiration.

The air within the apparatus was assumed to be saturated. It was not possible within the experimental routine to make measurements on both wet- and dry-bulb thermocouples. On only one occasion, in a pilot exposure, were dry and wet thermocouple readings taken, and the results indicate full or nearly full saturation.

\section{Results}

Figs. 1a and $b$ show the mean inspired air temperature curves for each type of apparatus at each environmental condition for all tests in which the men performed Task $A$. The mean initial and final rectal temperatures for men wearing either type of apparatus were not significantly different. The horizontal line $38 \cdot 8^{\circ} \mathrm{C}$. $\left(101 \cdot 8^{\circ} \mathrm{F}\right.$.) shows the mean rectal temperature at the conclusion of these experiments. It can be seen that while the curves show some scatter, the pattern in each case with each apparatus is very similar.

Fig. 2 shows the mean inspired air temperature curves of all the tests in which all the men took part while doing Task $A$ in either apparatus. In the experiments at higher temperatures, the men were unable to complete 65 minutes, so that the number of readings represented by each mean falls from the rest period towards the end of the experiment, although the number of readings in each mean never falls below 22. The curves of inspired air temperatures for individual experiments follow the same pattern as the mean curves shown in Figs. 1 and 2.

Fig. 3 shows the mean of the first recorded inspired air temperatures at each of the six environments investigated. These readings were taken five minutes after entering the hot room, during the first minute rest after walking for four minutes at 2 m.p.h. Since the men had performed the same task in those five minutes on each occasion, presumably the mean measurements shown reflect the rise in temperature due to environmental temperature. The difference shown in initial inspired air temperatures between the two types of apparatus is probably due to the different $\mathrm{CO}_{2}$ absorbents used, and to differences in the heat capacities in the two types of apparatus.

Whereas the environmental temperature influences the initial temperature of the air within the apparatus, the two types of equipment follow distinct and characteristic curves (Fig. 2) so that the inspired air in Apparatus 1 increases more rapidly and is about $5^{\circ} \mathrm{C}$. $\left(9^{\circ} \mathrm{F}\right.$.) higher after 40 minutes than in Apparatus 2, and this difference increases to about $8^{\circ} \mathrm{C}$. $\left(14^{\circ} 5 \cdot \mathrm{F}\right.$.).

Considering again the averages of all the experiments with Task A, in all six environments (Fig. 2) we see that the inspired air temperature in Apparatus 1 starts lower than that in Apparatus 2, but rises more quickly, passes that of Apparatus 2 in 20 
Fig. 1 ( $a$ and $b$ ) - Inspired air temperature in two types of breathing apparatus during work in various saturated environments.

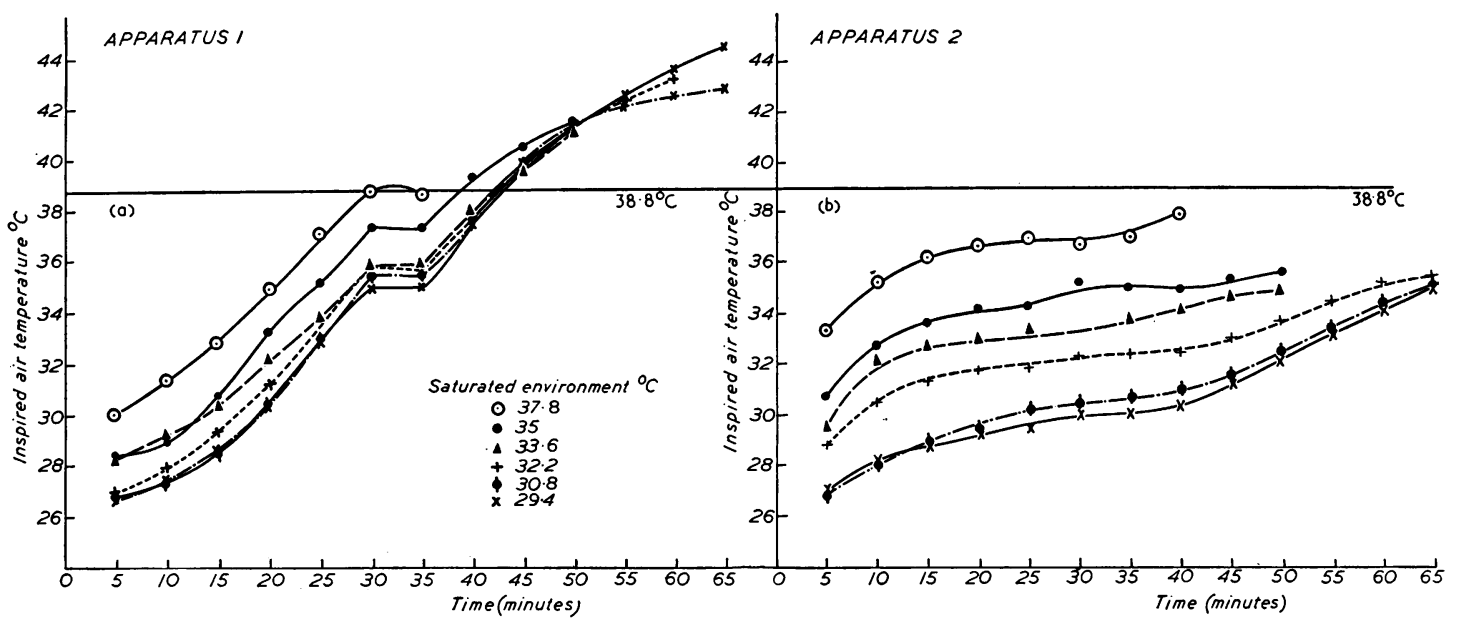

minutes (Fig. 2), passes rectal temperature in about 40 minutes, and reaches a mean peak of $43.7^{\circ} \mathrm{C}$. $\left(110^{\circ}\right.$ F.) after 65 minutes. In Apparatus 2 the temperature rises more slowly but steadily until finally $36 \cdot 3^{\circ} \mathrm{C}$. $\left(97 \cdot 3^{\circ} \mathrm{F}\right.$.) is reached after 65 minutes. From these curves Apparatus 2 is obviously the more efficient apparatus in maintaining low inspired air temperatures, despite the fact that by using caustic soda as a $\mathrm{CO}_{2}$ absorbent it has a greater amount of heat generated within the circuit.

In all the experiments with subjects performing Task A, men wearing Apparatus 1 finished with inspired air temperatures lower than $40^{\circ} \mathrm{C}$. eight times in 54 individual experiments, and only twice with temperatures lower than $38.8^{\circ} \mathrm{C}$. (the final rectal temperature). All these cases occurred at the two highest temperatures, $35^{\circ}$ and $37.8^{\circ} \mathrm{C}$., saturated environments, when the short period of survival in those environments did not allow the inspired air temperature to rise to this level, despite the higher initial starting temperature. In men wearing Apparatus 2, the inspired air temperatures surpassed $40^{\circ} \mathrm{C}$. only three times in 54 individual experiments, twice by the same man. On only five occasions in 54 experiments did they surpass $38 \cdot 8^{\circ} \mathrm{C}$.; these occurred in saturated environments at $29 \cdot 4,30 \cdot 8$, and $37 \cdot 8^{\circ} \mathrm{C}$.

Fig. 4 shows the mean inspired air temperatures for the 12 men who performed Task B in a saturated environment at $37 \cdot 8^{\circ} \mathrm{C}$. $\left(100^{\circ} \mathrm{F}\right.$. $)$.

FIG. 2.-Inspired air temperature recorded in both types of apparatus while subjects performed Task A (mean values).

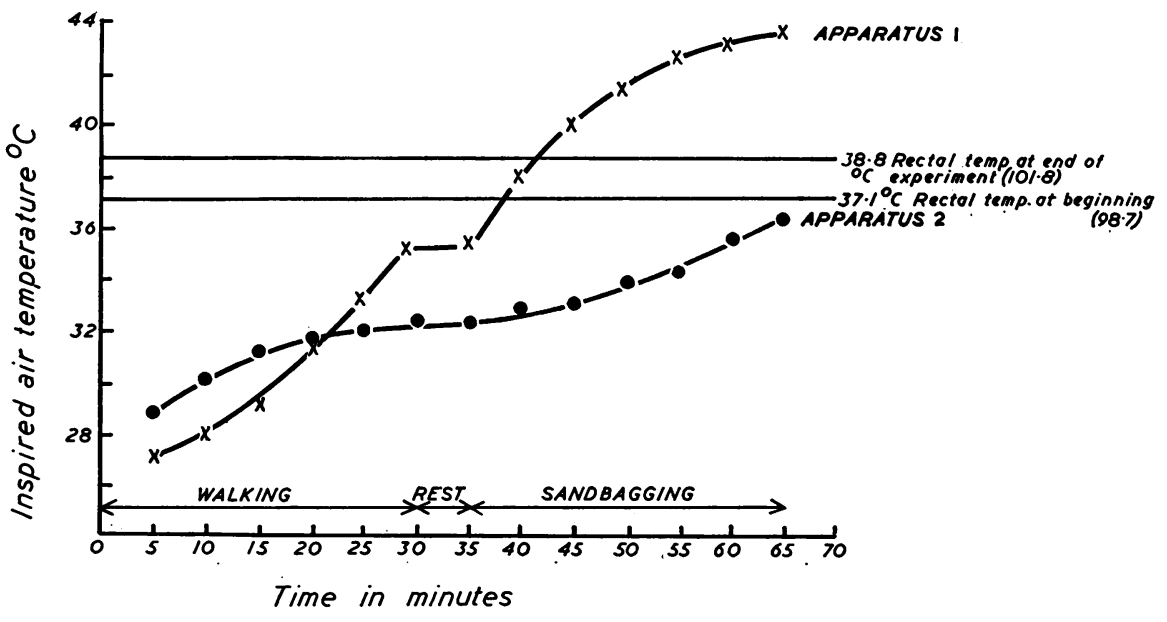


FIG. 3.-Increase in first recorded inspired air temperature (after five minutes in chamber) due to increase in environmental tempera. ture (mean values).

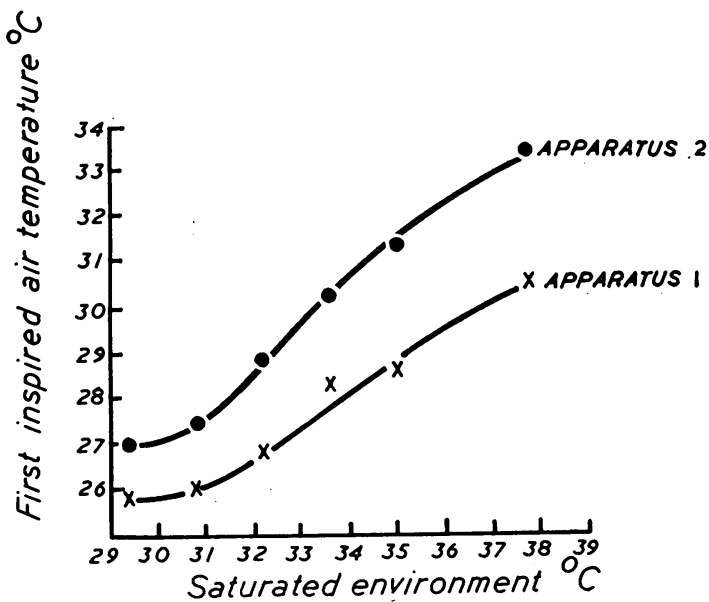

When the men were performing Task $B$ the temperature of inspired air in both types of apparatus rose more rapidly than when they performed Task A, and although the men could not continue working for longer than half an hour, with both types of apparatus the inspired air temperature rose above body temperature. The temperatures shown for Apparatus 2 reached a higher value than expected, largely because the last two points represent a mean of only three and two subjects respectively, one of whom had an unusually high inspired air temperature.

The subjects were asked before the start of each experiment to indicate by a sign if and when they considered that the inspired air had become uncomfortably hot. After the experiments each man was questioned on this point, whether or not he had

Fig. 4.-Inspired air temperature recorded in both types of apparatus while subjects performed Task $B$ (mean values).

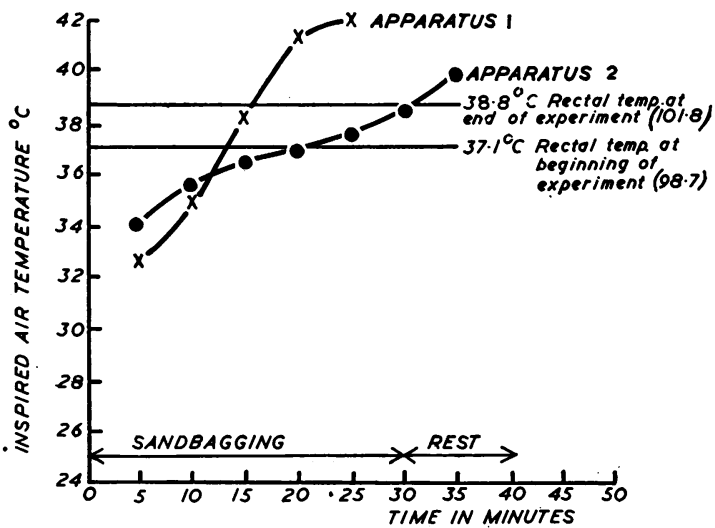

already volunteered such information. The men were found to be firm in their views and questioning revealed not one who wished to change his mind. Only one complaint was volunteered by a wearer of Apparatus 2, when, after 55 minutes of work, the inspired air temperature reached $42^{\circ} \mathrm{C}$., subsequently reaching $43^{\circ} \mathrm{C}$. at the end of the experiment. In Apparatus 1, in 33 of the 54 individual experiments the subjects volunteered the information that the air had become uncomfortably hot. During any individual experiment, the temperature of the inspired air regarded as that at which the subject complained was that taken during the minute rest subsequent to the receipt of the information. These temperatures ranged from 39 to $43^{\circ}$ C. $(102.2$ to $109 \cdot 4^{\circ} \mathrm{F}$.). The final temperatures achieved by those subjects who did not feel that the inspired air was uncomfortably hot ranged from 38 to $42 \cdot 25^{\circ} \mathrm{C}$. $\left(99.95\right.$ to $108.05^{\circ}$ F.). Whether or not complaints were made, most of the subjects considered that they could have continued for a longer period if the temperature of the inspired air had not been so high.

The "tolerance time" of the men in all these experiments shows that the wearers of Apparatus 1 were able to continue work for an average of 50 minutes, and the wearers of Apparatus 2 continued for one of 54.5 minutes, or $9 \%$ longer.

\section{Discussion}

Although it is recognized that each type of apparatus has its special merits in use, the physiological significances of the inspired air temperature in these conditions are clear. When the inspired air temperature reaches body temperature, this channel of heat loss is denied to the thermoregulatory system, and when it rises above body temperature the body is gaining heat through the lungs. When men are wearing either type of breathing apparatus a large part of the trunk is shielded and evaporative cooling from this area is considerably reduced, so that in environments where dissipation of heat by evaporation is already restricted, the normally unimportant role of cooling by evaporation of exhaled air assumes greater significance. If it is possible to achieve an environmental temperature at which all heat exchanges between body and environment are prevented, then the rate of production of heat within the body itself, i.e., the rate of expenditure of energy, will determine the tolerance time. If the breathing apparatus is worn when the inspired air temperature is below body temperature the expected tolerance time will be lengthened, and when the inspired air temperature is above body temperature, then the expected tolerance time will be shortened. 
It is evident from the results obtained in the present series of experiments that, disregarding for the moment other merits of the apparatus, when the inspired air temperature alone is considered, Apparatus 1 had a detrimental effect on the wearer after about 40 minutes, i.e., for 25 minutes of the 65-minute task, while Apparatus 2 did not impose this physiological burden. An examination of the rates of rise of temperatures (see Figs. 2 and 4) in the breathing circuit indicates, as expected, that the demand for oxygen and the rate of production of $\mathrm{CO}_{2}$ and therefore of $\mathrm{CO}_{2}$ absorption by sodalime or caustic soda and resulting production of heat closely controls the inspired air temperature. This is more evident in the curves for Apparatus 1 than for Apparatus 2, and probably reflects the relative efficiency of the methods of cooling the air in the circuit. During the five minutes' rest period in the experiment, the temperature either remains steady or falls. During Task B, in which the men start with the heavier work routine, the rate of rise of temperature is noticeably greater, but the rate of rise of temperature in Apparatus 1 at the lighter work routine is disproportionate to an extent which makes it seem probable that if the lighter work had been continued there would have been a greater difference in the tolerance times of the subjects wearing the different types of apparatus.

Much of the blame for the inspired air temperature in Apparatus 1 rising so dramatically is due to the inefficient design of the cooler. Inspection of the cooler after the experiments showed that the coolant was never more than $60 \%$ liquefied, seldom more than $40 \%$ liquefied, and in a number of instances no liquefaction was evident. It seems likely that with an efficient cooler the inspired air temperature may well be reduced, although there is also some indication that even in full efficiency, a chemical cooling method of this type may not provide the best answer; this will obviously be true of higher environmental temperatures, where the environment itself will affect the coolant.

The inspired air temperature at which discomfort was experienced in the present experiments is much lower than the figures quoted by Haldane or Killick. Haldane found that when men were exposed to and breathed a saturated temperature of $54.5^{\circ} \mathrm{C}$. $\left(130^{\circ} \mathrm{F}\right.$.) ordinary breathing was more or less painful, that at a saturated temperature of $48 \cdot 9^{\circ} \mathrm{C}$. $\left(120^{\circ} \mathrm{F}\right.$.) work was hardly possible, but that at $45^{\circ} \mathrm{C}$. $\left(113^{\circ} \mathrm{F}\right.$. $)$ saturated temperature, "the air was not too hot to breathe pretty freely" even when quite hard work was done. Haldane and his subjects were completely exposed to these climates in a hot chamber. Killick, whose subjects were in a cool environment and breathed hot, moist air through a tube, found that for men at rest the lowest temperature which caused discomfort was $54.5^{\circ} \mathrm{C}$. $\left(130^{\circ} \mathrm{F}\right.$.), and, for men doing quite hard work, this limit dropped to $51.5^{\circ} \mathrm{C}$. $\left(125^{\circ} \mathrm{F}\right.$.). In the present investigation, where the subjects were exposed to saturated environments at various temperatures while wearing self-contained breathing apparatus, respiratory discomfort was felt first at $39^{\circ} \mathrm{C}$., $6^{\circ} \mathrm{C}$. lower than the figure quoted by Haldane, and $12^{\circ} \mathrm{C}$. below that quoted by Killick. It is likely that the explanation for this lies in three factors : (1) the levels of comfort are reduced with an increase in the rate of work, and the "sandbagging" routine of the present experiments is very heavy work ; (2) the men during the present series were wearing apparatus, and that some of the discomfort noticed may have been due to soda-lime dust reaching the throat ; (3) the individual variation in the subjects used in the present series is greater than that of the subjects used by Killick or Haldane.

In deciding which type of apparatus is to be used, the effects of high inspired air temperature must be balanced against the practical advantages and disadvantages not specified here, paramount in which is the safety of the wearer.

\section{Summary}

Inspired air temperatures in two types of selfbreathing apparatus are given for men working at two different tasks in various saturated environments.

From these results it is shown that in the present design, so far as inspired air temperatures are concerned, wearers of Apparatus 1 are at a physiological disadvantage compared to the wearers of Apparatus 2. It must be emphasized that this refers only to the effects of inspired air temperatures, and other comparisons are necessary for true evaluation of the relative worth of the two types of apparatus in operational conditions.

There is some evidence to suggest that the figures previously obtained for saturated temperatures which men can breathe in comfort when they are working may not apply to wearers of closed-circuit breathing apparatus.

I wish to thank Dr. J. S. Weiner and Mr. R. F. Hellon, of the Medical Research Council's Climatic and Working Efficiency Unit in Oxford, for help and advice, and the National Coal Board, who provided administrative and experimental services, and finally the 36 subjects without whose whole-hearted cooperation these experiments would not have been possible.

\section{REFERENCES}

Haldane, J. S. (1915). Trans. Inst. of Mining Engineers (1914-15), 48,

Killick, E. M. (1932). J. Hyg., Camb., 32, 332. 